\title{
Using UAV-SfM to monitor the dynamic evolution of a beach on Penghu Islands
}

\author{
Cheng-Hao Lu ${ }^{1, *}$ and Shyh-Jeng Chyi ${ }^{2}$ \\ ${ }^{1}$ Department of Tourism and Leisure, National Penghu University of Science and Technology, Penghu County, Taiwan \\ ${ }^{2}$ Department of Geography, National Kaohsiung Normal University, Kaohsiung City, Taiwan
}

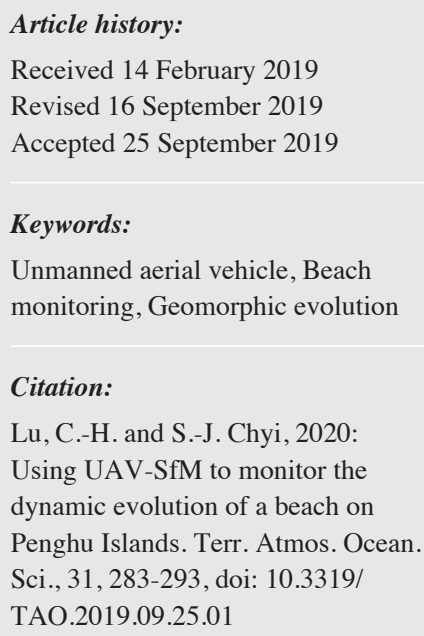

\begin{abstract}
This paper explores the combination of unmanned aerial vehicle (UAV) photogrammetry and an e-GNSS survey to investigate the short-term geomorphic change and dynamic evolution of a beach system in 2015. The RMS values of the ground control points and checkpoints validate that the accuracy of UAV-SfM photogrammetry is suitable for the rapid and frequent acquisition of 3D survey data from a beach environment. We produced four digital surface models (DSMs) to determine the short-term beach topographic response to well-known western Pacific typhoons, the NE monsoon and anthropogenic construction using multitemporal surface analysis. We investigated the magnitude of the erosion caused by intense typhoons; however, the beach-dune system generally recovers through sediment transport processes in winter. Beach monitoring also reveals that the overall sand volume of this beach was reducing in short-term period. Given that the sand budget of Shanshui beach would have been continuing to reduce, this may be a negative warning to this precious tourism resource. The dynamic evolution of this beach may result in the formation of a tombolo. This study demonstrates the feasibility and survey efficiency of UAV-SfM photogrammetry for coastal monitoring, and the technique will contribute to identifying the risk to beach systems and will benefit sustainable coastal management.
\end{abstract}

\section{INTRODUCTION}

The progressive advances in three-dimensional topographical reconstruction technology enhance our understanding of the morphodynamic changes and response behaviors of coastal environments to complex processes, such as typhoons, sea-level rise, and human activities. This issue is particularly significant and highly complex in coastal areas where frontal dunes and beaches are present. A beach is an unconsolidated deposit of sand and gravel on the shore, which is a sensitive equilibrium system subject to change (Bird 1996; Davidson-Arnott 2010). This system plays an important role in the natural protection against coastal inundation that is caused by extreme climate events. However, recent research has found that strong typhoons, storm surges, rising sea level, and anthropogenic construction contribute to severe and rapid beach erosion and changes in the coastal profile, even evolving from a depositional beach

\footnotetext{
* Corresponding author

E-mail:luch@gms.npu.edu.tw
}

to an erosive rocky coast (Hanson et al. 2002; Hapke et al. 2013; Harley and Ciavola 2013; Hanley et al. 2014; Dissanayake et al. 2015; Gonçalves and Henriques 2015). Once the beach/dune system experiences regression, intense climate events cause damage to the coastal environment, and this poses an issue for coastal safety and sustainable development. Beach erosion and degradation present important challenges for coastal communities, the infrastructure and wetlands (Taveira-Pinto et al. 2011). Therefore, to efficiently manage the coastal zone, accurate and frequent surveys must be carried out to detect the geomorphic changes to a beach system. This process will help identify, quantify and forecast the coastal evolution and evaluate its impact.

Accurate and frequent geomorphic data must be collected to monitor the beach volume change and to identify the causes of coastal evolution. However, repeated surveys may be difficult in the coastal environment due to accessibility, the lack of a permanent benchmark, and the cost and time involved (Mason et al. 2000; Sturdivant et al. 2017). The coastal environment coupled with strong winds can 
also limit aerial-based surveys. Recently, the availability of structure-from-motion (SfM) photogrammetry and unmanned aerial vehicles (UAVs) has offered an effective and accurate method to produce dense point clouds, high-resolution orthomosaics and a digital surface model (DSM) for coastal monitoring. This method can provide a low-cost solution for beach monitoring and help identify the processes related to natural and/or human-related topographic beach changes (Brunier et al. 2016; Casella et al. 2016; Chen et al. 2018; Pikelj et al. 2018). Furthermore, the vertical accuracy of UAV-SfM photogrammetry has been demonstrated to be comparable with the results generated by terrestrial laser scanning (Mancini et al. 2013; Gruszczyński et al. 2017). Despite the capacity of UAV-SfM to survey inaccessible coastal areas, windy weather conditions pose severe difficulties to UAV operation, especially for small and light UAVs. To overcome the weather limitations, e-GNSS positioning based on a network may be an alternative way to achieve accurate and fast surveys without costly investment or long processing times based on terrestrial laser scanning or airborne LIDAR (Harley et al. 2011). Furthermore, eGNSS surveys can be implemented in windy weather conditions, but this technique suffers from limited measurable points for DSM construction.

In this study, we combine UAV-SfM photogrammetry and e-GNSS surveys in a repeated investigation of geomorphic change on Shanshui beach. Shanshui beach is a highly dynamic beach on Penghu Islands, Taiwan, that is affected by typhoons and strong north-east monsoons. To monitor morphological and volume changes to the beach and quantify sediment budgets, SfM photogrammetry was applied to aerial imagery acquired using a multi-motor unmanned aerial vehicle in the low wind seasons of spring, summer and autumn. In the high wind winter season, the e-GNSS survey was used to measure points on the beach. This study first evaluates the accuracy of UAV-SfM photogrammetry by calculating the horizontal and vertical RMS errors of ground control points and checkpoints. We then produce four digital surface models (DSMs) and sediment budgets for the beach via multitemporal surface analysis. Based on the results of the analysis, we detect the morphological changes to the beach and determine short-term beach topographic responses to well-known western Pacific typhoons and anthropogenic construction. Finally, we identify the dynamic evolution of the beach/dune system and evaluate the possible impact arising from these influencing factors.

\section{STUDY AREA}

Shanshui beach is located on the southern coast of the Penghu main island, Taiwan (Fig. 1). This beach is characterized by a steep beach-face, with an average slope of approximately $8-10 \%$. The beach extends for approximately $750 \mathrm{~m}$ and its average width is $100 \mathrm{~m}$, varying from 50 to
$200 \mathrm{~m}$. Sediments are medium to very coarse sands, which are composed of the fragments of coral reefs, seashells, foraminifera, and basalt clasts. The western side of the beach is a wetland with high biodiversity that provides ecosystem services to local and migrant species.

Shanshui beach has a mesotidal range of approximately 2.2 to $2.9 \mathrm{~m}$ during spring tides. Observations from the tidal gauge established by the Central Weather Bureau from 1955 to 2015 indicate that the maximal storm tidal level from typhoon surges is $1.8 \mathrm{~m}$ above mean sea level (MSL) (Central Weather Bureau 2016, 2017). Based on these observations, the highest wave was approximately $6.84 \mathrm{~m}$ and the average significant wave height was $1.22 \mathrm{~m}$ from 2006 to 2017. The average wave height during winter is $1.7 \mathrm{~m}$, and $40 \%$ of the waves range from 1.5 to $2 \mathrm{~m}$ because of the strong northeastern monsoon. During summer, the average wave height is $0.6 \mathrm{~m}$ and more than $60 \%$ of the waves are less than $0.6 \mathrm{~m}$.

Taiwan experiences frequent typhoon activity, with 3 to 4 typhoons passing annually across or by the island, frequently reaching the maximum intensity of a category five/super typhoon (Shieh et al. 1998). During the investigation period in 2015, two tropical storms named Linfa and Chan-hom struck Penghu Island. Category 1 Tropical Storm Linfa was a tropical cyclone that developed on 1 July in the Philippine Sea, eventually landing at Penghu Islands and Taiwan on 9 July. At almost the same time, Category 4 Typhoon Chan-hom was a large, powerful and long-lived tropical cyclone that affected most countries in the western Pacific basin. These two powerful storms caused extreme wave heights and clear beach erosion. Two UAV-SfM photogrammetry studies were carried out to identify the influence of the storms.

Shanshui beach is a famous tourist attraction, and a densely populated coastal community is located inland from the beach. According to an interview with a local elderly man, the beach appears to have suffered degradation after the construction of the eastern fish harbor. Therefore, to facilitate effective coastal management and sustainable development, a detailed investigation and monitoring of the beach evolution is essential.

\section{METHODOLOGY}

\subsection{UAV-SfM Survey}

A four-axis hexacopter equipped with an Olympus EPL2 digital camera with a $17.3 \times 13.0 \mathrm{~mm}$ CMOS sensor was used to obtain 1631 images (13.1-megapixel JPEG files). We selected a M.ZUIKO $12 \mathrm{~mm}$ fixed-focus to produce the pictures. The flight plans were chosen with the autopilot along east-west transects according to a defined 90\% frontal overlap and 70\% side overlap (Fig. 1c). The images were taken with a near-nadir look angle at approximately 50 m altitude on 2 May 2015, 15 July 2015, and 2 
October 2015. The former two datasets of UAV photogrammetry were conducted to identify beach changes pre- and post-storm, quantifying and determining the rapid response to extreme storms. The study area covered approximately $700 \times 100 \mathrm{~m}$ and required two flights to achieve a ground sampling distance (GSD) of $1.8 \mathrm{~cm}$ pixel resolution.

Prior to each flight, we deployed 14 well-distributed ground control points (GCPs) for georeferencing and the optimization of aerotriangulation in the photogrammetric workflow (Fig. 1c). We also placed 10 checkpoints (CPs) to evaluate the RMSE. The GCPs and CPs were designed with a checkered black and white pattern and cross-shaped $60 \mathrm{~cm}^{2}$ targets, and we surveyed the positions of their center using Trimble R6-4 GNSS receivers and e-GNSS positioning, offered by the National Land Surveying and Mapping Center of Ministry of the Interior (MOI), Taiwan. The GCPs and CPs had an average horizontal error of $0.8 \mathrm{~cm}$ and a vertical error of $1.3 \mathrm{~cm}$. Among the 14 GCPs, 9 GCPs (A2
- A8, A11) were planned as a fixed permanent benchmark (Fig. 1c) for future use as site calibration between different surveys.

The SfM photogrammetry workflow was implemented in Agisoft Photoscan Professional (v1.1, Agisoft LLC, St. Petersburg, Russia). Agisoft Photoscan software was chosen to reconstruct the 3D scene geometry of Shanshui beach because SfM pertinent algorithms are well-established and all the SfM protocol stages have detailed information, error control and reports. Many recent studies have also applied this software to conduct landform monitoring (Javernick et al. 2014; Lucieer et al. 2014; Warrick et al. 2017; Westoby et al. 2018). This software combines structure-from-motion with multiview stereo methods (SfM-MVS), which are part of recent progress in computer vision algorithms.

The reconstruction of the ground surface and objects by PhotoScan is a three-step process that includes photo alignment and geo-registration to GCPs and, finally, dense point (a)

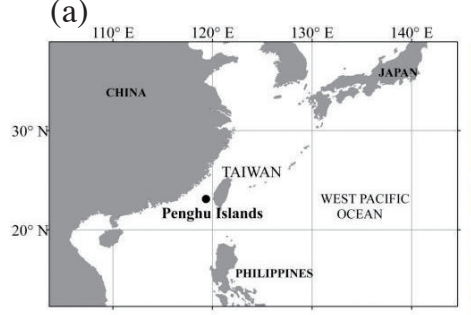

(c)

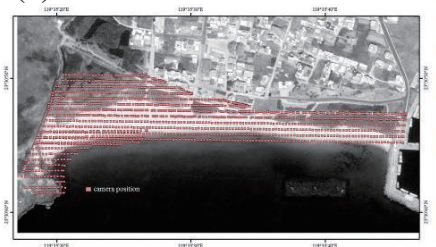

(d) (b)

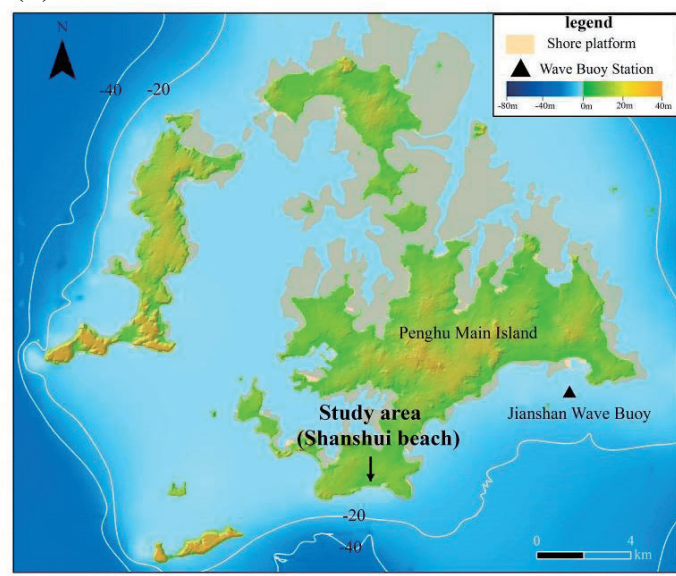

$110^{\circ} 35^{3} 30^{\circ} \mathrm{E}$

$110^{\circ} 3^{5} 40^{\mathrm{NE}}$

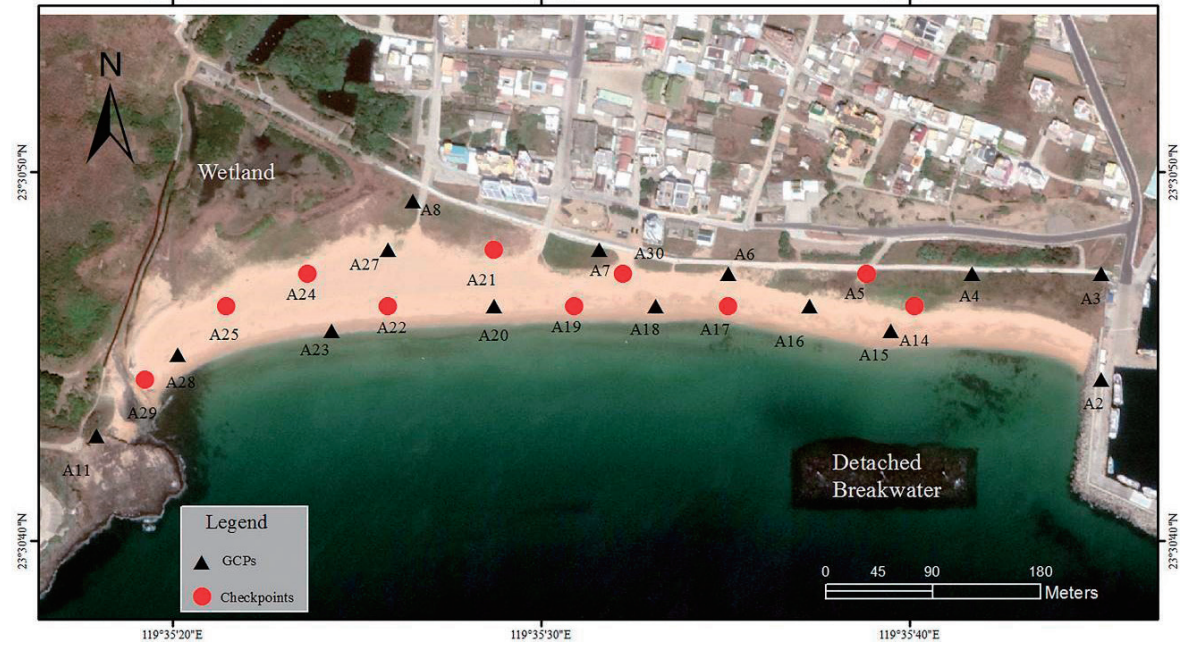

Fig. 1. Location of the study area. (a) Shanshui beach is located on the southern coast of the main island, Magong on Penghu Islands. (b) The beach is oriented from $\mathrm{E}$ to $\mathrm{W}$ and is $750 \mathrm{~m}$ in length. Towards the east, the beach transitions into an artificial fish harbor. Due to the construction of the navigation lighthouse in the harbor, the detached breakwater was placed. (c) The red square represents the camera position of 1631 images acquired at 50 m altitude by the UAV. (d) The black triangle represents the 14 ground control points (GCPs) and the red circle represents the 10 checkpoints (CPs). 
cloud, DSM and orthoimage construction (Agisoft 2018). The first stage is to import the images and conduct image alignment. After importing the images, the software obtains the approximate interior orientation parameters from the EXIF header of the images to facilitate the search for conjugate points and parameters including the sensor size and focal length. Image alignment then detects conjugate points on unique features of objects in the image by automatically using the Scale Invariant Feature Transform (SIFT) algorithm, an object recognition system (Lowe 2004). A network bundle adjustment is performed based on the detection of conjugate points (known as the sparse point cloud) and then the consecutive images are aligned to recover the camera position in a relative coordinate system. The next procedure is to transform the sparse point cloud into an absolute spatial reference by placing the GCPs into the area of interest. Next, the optimization process is implemented on the sparse cloud, it is georeferenced and the accuracy of the sparse cloud model is significantly enhanced. Following this step, the accuracy of the transformed model can be checked by deploying checkpoints. The final stage consists of building the dense point cloud and exporting the DSM and orthoimages. We performed the highest quality reconstruction for the dense point cloud, producing an average density of 230 points $\mathrm{m}^{-2}$. When we built dense cloud, we chose aggressive depth filtering. The dense point cloud was manually edited prior to producing the DSM at $10 \mathrm{~cm}$ resolution using an Inverse Distance Weighted algorithm for interpolation. The orthomosaic image was also generated using PhotoScan's mosaic blending mode at $10 \mathrm{~cm}$ resolution. Why we chose this resolution? The reason are that firstly we hope to obtain the multi-temporal, high-resolution and accurate DSM and orthoimages to understand the beach landform response to the typhoon event and other impact factors. Besides, the efficiency and time-consuming of UAV are also taken into consideration. Most important of all, after reviewing the accuracy evaluation of the UAS-SfM process, we found the maximum vertical RMS errors of checkpoint is $4.8 \mathrm{~cm}$ (point A25). Therefore, we use about double value of the maximum vertical RMS errors as the cell size of the DSM.

\subsection{E-GNSS Survey}

The wind is a limiting factor in coastal areas, especially on the coast of Penghu Islands where the winter NE monsoon wind speed is greater than $14 \mathrm{~m} \mathrm{~s}^{-1}$ and often exceeds the safety conditions of using UAV. To overcome the limitation of the UAV in winter, we applied an e-GNSS survey to allow us to complete the analysis. Although the drawback of an e-GNSS survey is that it cannot obtain many measurable points, this method does offer accurate and fast results. The e-GNSS survey combines the technologies of the internet, wireless communication and GPS positioning, using the virtual base station of the real-time kinematic (VBS-
RTK) positioning system to achieve a high precision survey. Based on the validation of the accuracy, the e-GNSS positioning precision is approximately $2 \mathrm{~cm}$ in horizontal coordinates and approximately $5 \mathrm{~cm}$ in ellipsoidal heights.

Topographic data were obtained at 5-m intervals along 14 east-west transects over the principal beach area. The Trimble R6-4 GNSS receivers were used for this study. The surveys took place during low tide on 20 December 2015. The horizontal positions were referenced to Taiwan Datum 1997/Transverse Mercator 2 degree (TM2) based on the Geodetic Reference System 1980 (GRS 80). The elevation reference was based on the Taiwan Vertical Datum 2001 (TWVD2001). The orthometric height of each point was calibrated using the known geoidal undulation provided by the National Land Surveying and Mapping Center, MOI. The dataset of measurable points had an average horizontal error of $0.8 \mathrm{~cm}$ and a vertical error of $1.3 \mathrm{~cm}$. In this study, we collected 603 sample points with a suitable dispersion by using E-GNSS survey in winter. We used the same interpolation method (IDW) with UAV-SfM. We interpolated these points and into DSMs with 1-m spatial resolution using ESRI ArcGIS software, while the cell size of UAV-SfM-based approach were also resampled to the same size. Finally, the winter beach DSM was compared with the DSMs derived from the UAV-SfM-based approach.

\section{RESULTS}

\subsection{Accuracy Evaluation of the UAS-SfM Process}

After implementing the SfM workflow, all $1631 \mathrm{im}$ ages were aligned and they produced a sparse point cloud of 3327271 feature points and a dense point cloud of 39974987 points. Based on the deployment of the 14 GCPs, bundle adjustment was performed to transform the sparse point cloud with relative coordinates into the Transverse Mercator projection 2 degree (TM2) absolute reference system. With respect to the RMS error value of the corresponding GCPs, the RMS values for all GCPs were $0.015 \mathrm{~m}$ in the east direction, $0.020 \mathrm{~m}$ in the north direction, and 0.018 in the vertical direction (Table 1 and Fig. 2a).

For a better understanding of the accuracy of the sparse point cloud model after bundle adjustment transformation, we placed 10 uniformly distributed checkpoints (CPs) over the study area for validation purposes. These CPs were not incorporated into the bundle adjustment calculation. The whole transformation resulted in RMS values of $0.021 \mathrm{~m}$ in the east direction, $0.027 \mathrm{~m}$ in the north direction, and 0.035 in the vertical direction (Table 1). The horizontal and vertical RMS errors of the bundle adjustment are less than $10 \mathrm{~cm}$, whereas the vertical accuracy of point A25 was only $4.8 \mathrm{~cm}$ (Fig. 2b). The accuracy results for the GCPs and CPs demonstrate that SfM-MVS photogrammetry is suitable for the rapid and frequent acquisition of 3D survey data in the beach environment. 

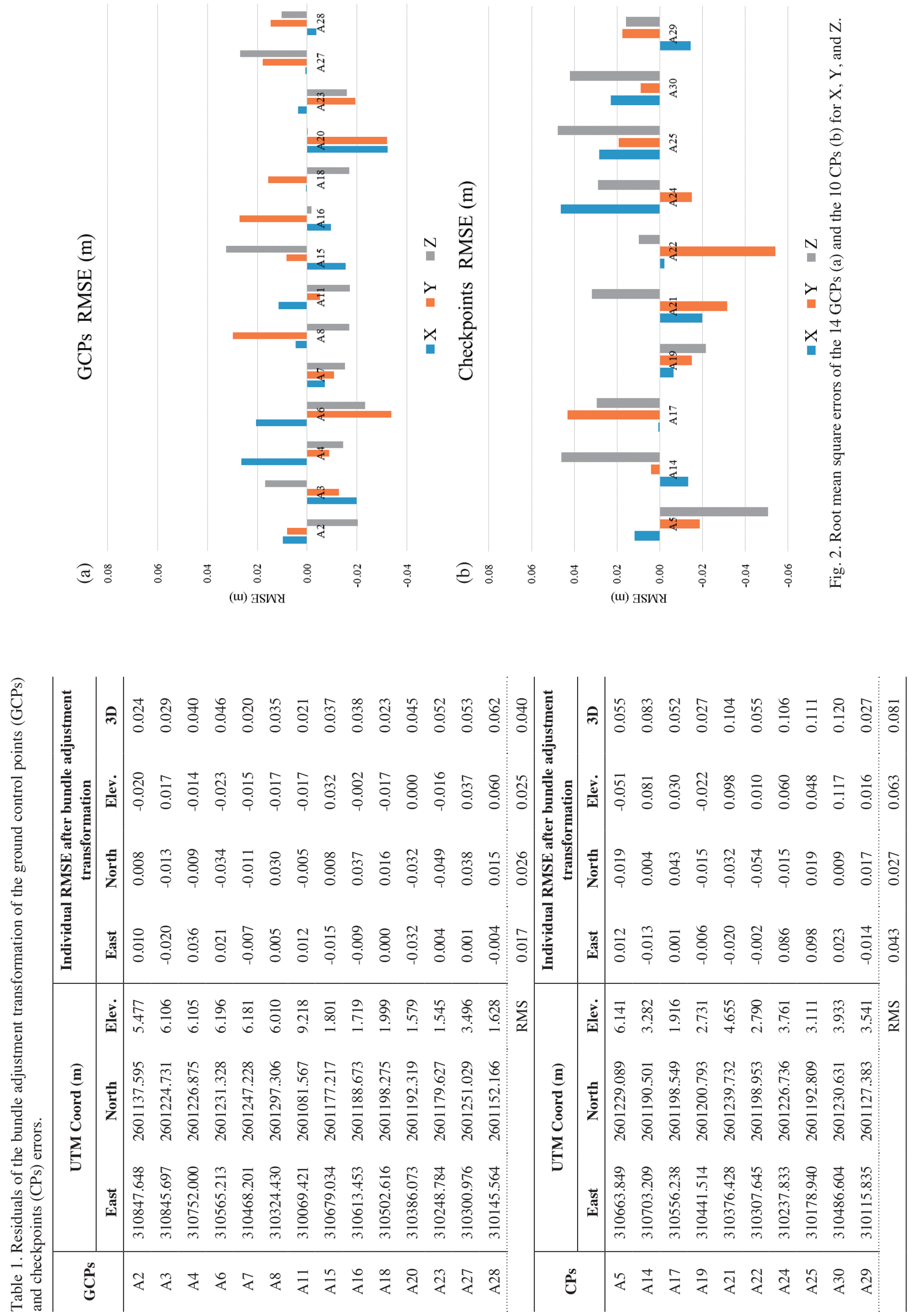


\subsection{The Result of Change in Beach Morphology}

This study compared the morphological changes and sediment budgets between May and December 2015 that were calculated from the multitemporal DSM dataset derived from UAV-SfM and the e-GNSS survey (Fig. 3a). Based on the results of the DSM comparison, we found volumetric and vertical variations at the beach and identified short-term beach topographic responses to well-known western Pacific typhoon, winter NE monsoons and anthropogenic construction. Figure $4 \mathrm{~b}$ depicts the morphological and volumetric changes caused by the two consecutive severe typhoon that occurred in July 2015. The DSM change analysis identified apparent beach degradation and retreat patterns linked to energetic waves, especially in the case of the largest magnitude change that occurred in the western sector of Shanshui beach.

The cross section profiles (Fig. 3b) show obvious difference of beach landform response to the environmental events between the western and eastern part of the beach. The western part of the beach (A-A') was serious eroded and retreated after the typhoon, while the eastern part (BB') was in a situation of deposition. The winter NE monsoon resulted in a recovery situation of sand accumulation in the beach face of the western part, while the profile of eastern part shows the overall lowering of the terrain. That is to say that the detached breakwater could not protect the eastern beach in winter. Notably, despite the shore face of western part was with up to $1 \mathrm{~m}$ of deposition, the berm was in a slightly lowering condition.

Figure 4 shows that the difference in DSMs (DoDs) in three successive morphological surveys were used to detect the beach geomorphic changes between the pre-typhoon and post- typhoon states (2015/05 - 07). The short-term geomorphic changes to the beach due to the winter NE monsoon $(2015 / 10-12)$ are also displayed (Fig. 4a). Figure 4b shows the volumetric variations in the beach budgets between different seasons and marine conditions. The values on the $\mathrm{x}$ axis indicate the sample profiles from west to east on the beach. The sample profile interval is approximately $25 \mathrm{~m}$ and calculated volumetric variations were determined for each profile. The results find that the volumetric differential displays a large loss of $23254 \mathrm{~m}^{3}$ in the western sector that highlights the storm process. Conversely, the eastern sector shows a accretion of $3900 \mathrm{~m}^{3}$, where the offshore breakwater may contribute by protecting the beach against erosion, with the longshore drift transferring sediment from the western sector of the beach.

With respect to the response of the beach to the strong $\mathrm{NE}$ monsoon in winter, interesting results indicate that the beach is in a state of accretion despite the strong and enduring wind. In particular, the western sector of the beach, where a large loss occurred owing to the summer typhoon, recovered gradually in winter. Figure 5, displaying two pho- tos of Shanshui beach on 14 July 2016 and 27 December 2016, shows erosion after the summer typhoons and accretion in winter. The left photo shows that the two typhoons caused $1.5 \mathrm{~m}$ of erosion in height. The right photo shows that the beach recovered to the same height as before the typhoon because of the NE monsoon. The volumetric differential displays a large accretion of $13364 \mathrm{~m}^{3}$ in the western sector between fall and winter. This variable beach morphology is typical of beach construction, which is related to the leeward location of this beach in winter.

\section{DISCUSSION}

\subsection{Beach Landform Response to the Variation of Typhoon Event and NE Monsoon}

The previous section finds that according to the field investigation and DoDs analysis, simultaneous erosion/ deposition occurring on the same beach. The western part of the beach was serious eroded and retreated after the typhoon, while the eastern part was in a situation of deposition. However, in winter only the western part of the beach was recovered and the eastern part was eroded despite this part is behind the detached breakwater.

We assume that the sediment change should be influenced by the local longshore drift, wave and wind. Therefore, we collected local observation statistics of wave and wind during the typhoon and winter NE monsoon to discuss the correlations between the landform response and environmental stimulation. The wave buoy established by the Institute of Harbor and Marine Technology (IHMT) from 2010 outside the Jinshan harbor in the southern coast. The Jinshan bouy recorded the observation of wave and wind simultaneously.

Based on the summer typhoon event of Fig. 6, we can clearly identify that the dominant direction of the wave is northward and eastward, this could induce the strong longshore current which make sediment transportation from western part of the beach. In contrast, the dominant direction of the winter wave is northward and westward, this could induce the westward longshore current. Therefore, due to the action of longshore drift, a general eastward movement of sediment from the drift caused by the strong energetic typhoon waves, while the eastern part of beach accumulated the sediment because the detached breakwater acts as obstruction of strong wave. However, during the NE monsoon in winter the longshore drift switches to westward, this resulted in the recovery of western part of beach. The rose diagrams of wave and wind were collected from the Jianshan Buoy, which implicated that predominant NE monsoon may induce the erosion of landward dune and beach berm in winter. In addition, the sediment from the eroding western part of beach also sources the sediment sink of landward dune.

Therefore, the observed erosion is attributed to the typhoon events. Nevertheless, the NE monsoon is the main process that allows the beach to recover. This study also 
(a)
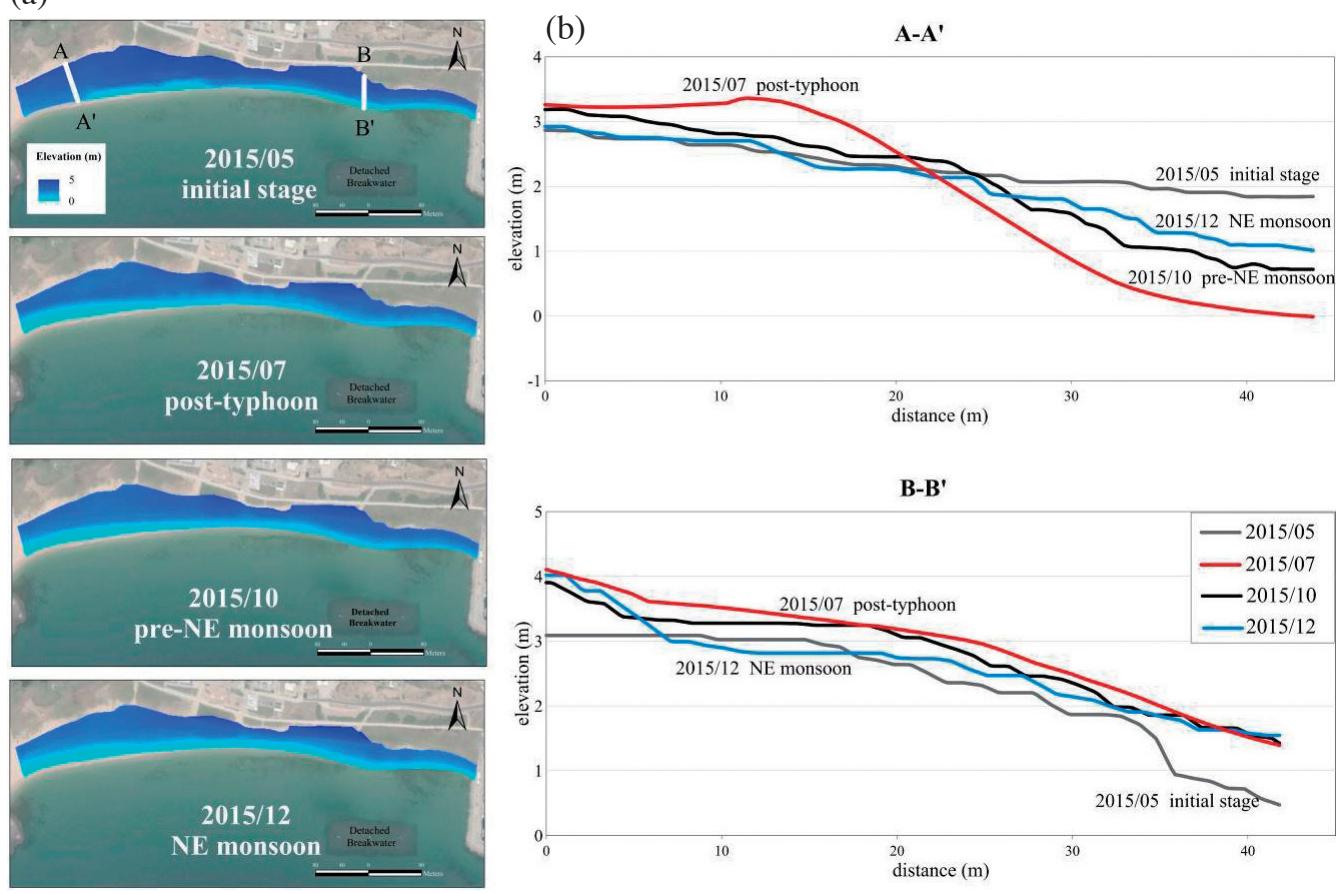

Fig. 3. (a) DSMs generated from UAV-SfM for 2015/05, 2015/07, 2015/10, and the e-GNSS survey for 2015/12. (b) Cross section of terrain profile in western (A-A') and eastern part (B-B') of the beach. The profiles show obvious difference of beach landform response to the environmental events between the western and eastern part of the beach.

(a)

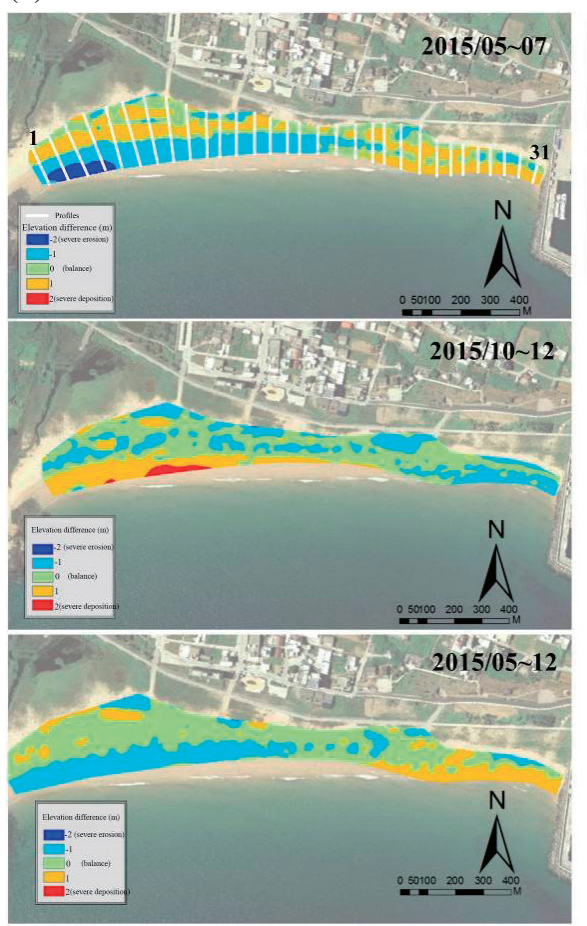

(b)
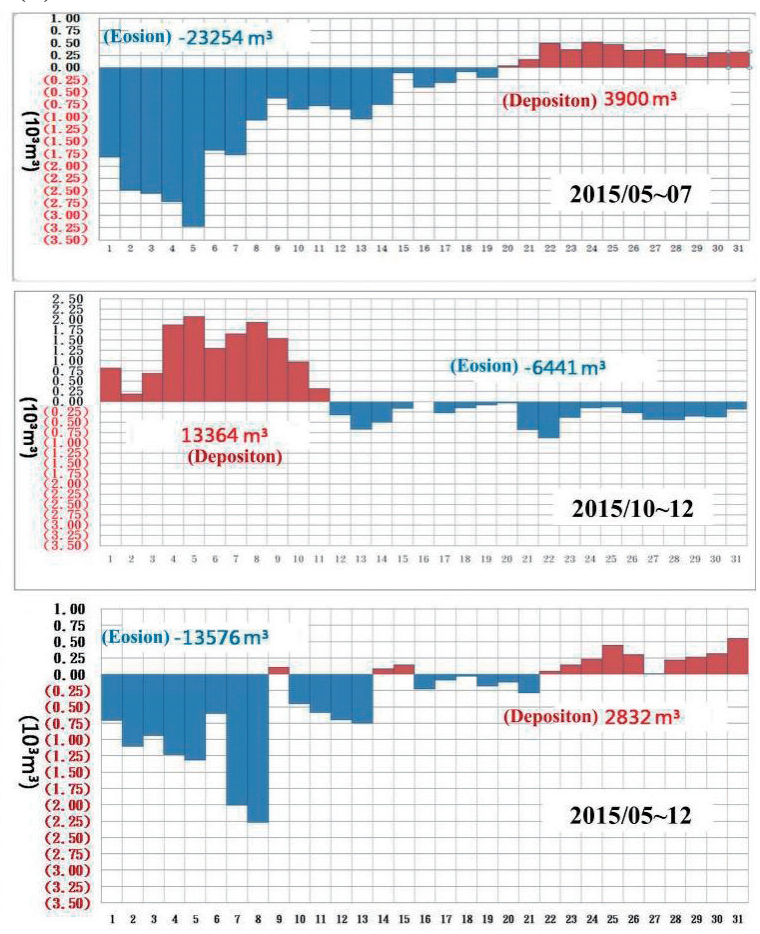

profile number

Fig. 4. (a) The DSMs of the differences (DoDs) in three successive morphological surveys were used to detect the beach geomorphic changes between the pre-typhoon and post-typhoon states (2015/05 - 07). The short-term geomorphic changes to the beach due to the winter NE monsoon (2015/07 - 12) are also displayed. Erosion is indicated in blue and deposition in red. (b) The volumetric variations in the beach budgets between different seasons and marine conditions. The values on the $\mathrm{x}$-axis indicate the sample profiles from west to east on the beach. The sample profile interval is approximately $25 \mathrm{~m}$ and calculated volumetric variations were determined for each profile. 


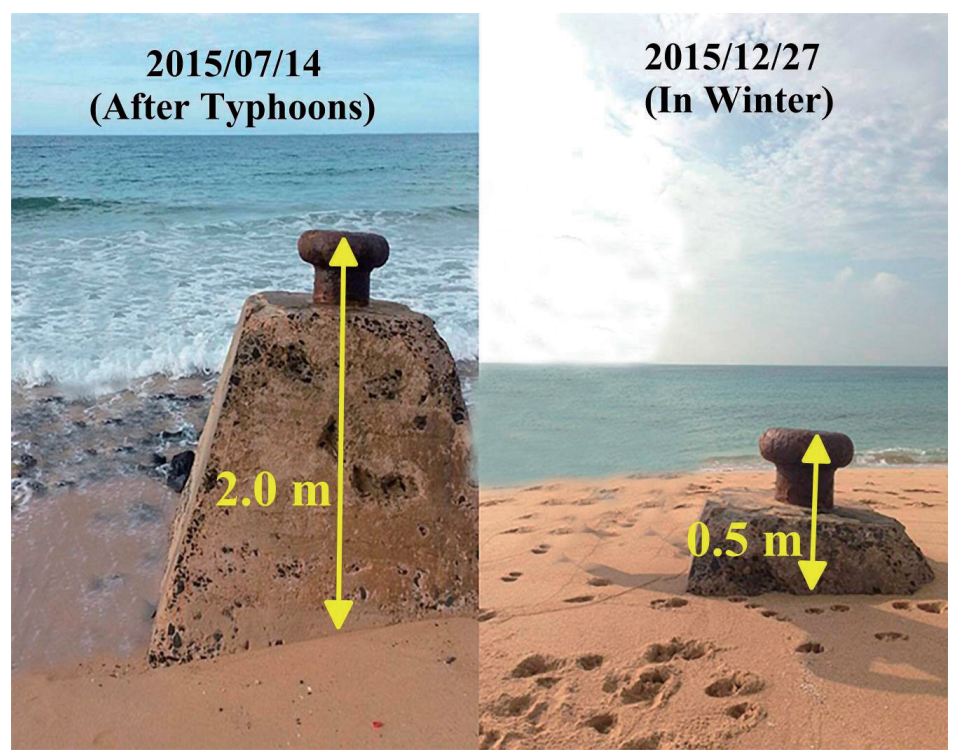

Fig. 5. Photos of Shanshui beach on 14 July 2015 and 27 December 2015, showing erosion after the summer typhoons and accretion in winter. The left photo shows that two typhoons caused $1.5 \mathrm{~m}$ of erosion in height. The right photo shows that the beach recovered to the same height as before the typhoon due to the NE monsoon.

(a)
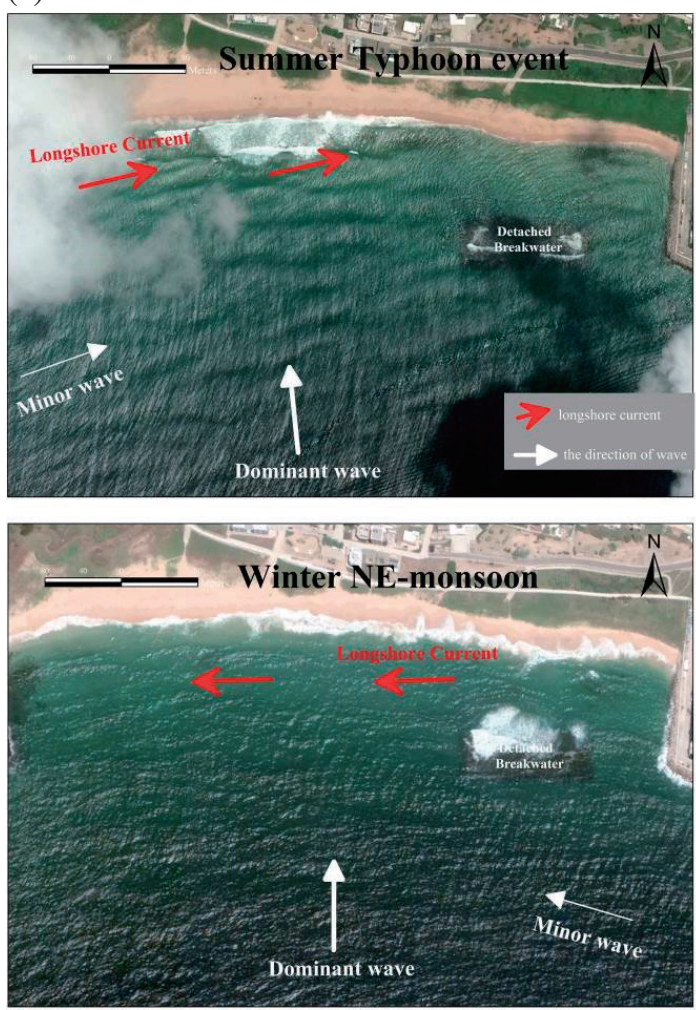

(b)

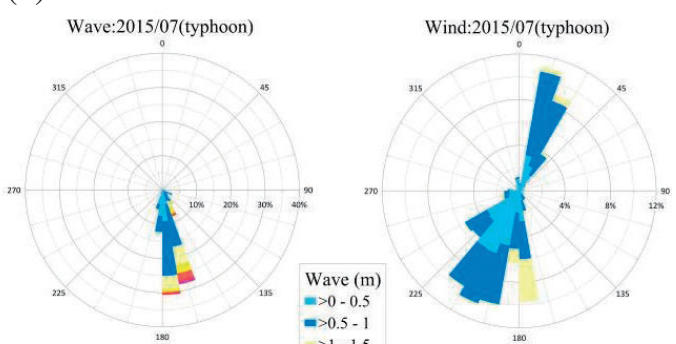

$\begin{array}{ccc}130 & =>0.5-1 & \\ \text { Wave:2015/10-12(NE monsoon) } & >1-1.5 & \text { Wind:2015/10-12(NE monsoon) } \\ & >1.5-2\end{array}$
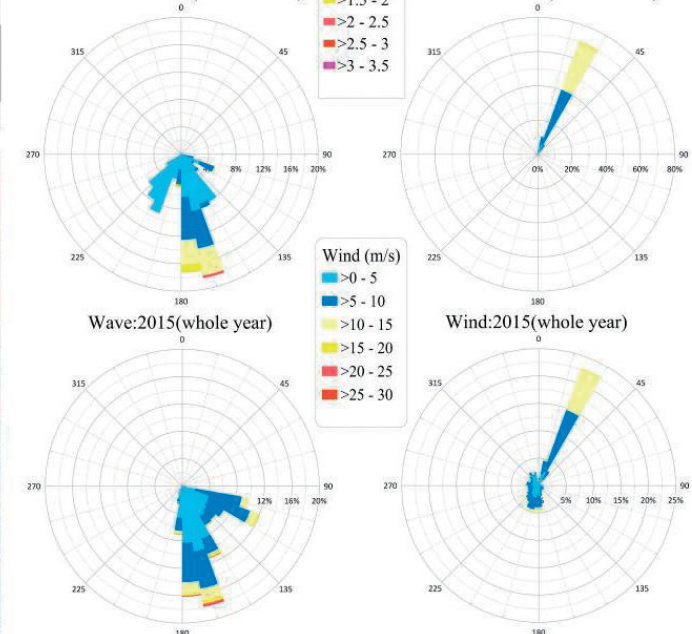

Fig. 6. The wave conditions and the rose diagrams of wave and wind. (a) The direction of wave and longshore drift in summer typhoon and winter NE monsoon. In summer typhoon event, northward wave was dominant on the satellite image with higher wave height and shorter wave length while the minor wave was from the eastward direction. The oblique wave could cause westward longshore drift to move sediment alongshore. In winter, northward wave was dominant and north-eastward wave was minor. This wave direction could cause eastward longshore drift. This show that the longshore drift switches between typhoon and NE monsoon, which may induce the change of the direction of sediment transportation. (b) The rose diagrams of wave and wind were collected from the Jianshan Buoy. In winter, predominant NE monsoon may induce the erosion of landward dune and beach berm. 
demonstrates that an intense storm can cause severe erosion of a beach system; however, the system generally recovers through onshore sediment transport processes in winter (Vousdoukas et al. 2012). Notably, despite the placement of the detached breakwater, the overall sand volume of this beach was reducing. Given that the sand budget of Shanshui beach would have been continuing to reduce, this may be a negative warning to this precious tourism resource.

\subsection{Dynamic Evolution of Shanshui Beach}

In terms of the spatial distribution of beach erosion and accretion, different erosion and accretion phenomena occurred along the beach. The volume of the eastern sector of the beach clearly increased with accretion, whereas the western sector was eroded and experienced retreat. The accretion in the eastern sector is likely related to the placement of the artificial offshore breakwater.

Based on recent studies (Sunamura and Mizuno 1987; Marriner et al. 2008; Mangor et al. 2017), when the ratio of the distance from the breakwater to the mainland shoreline (D) to the width of the breakwater (W) is less than 1.5 , sand accumulates gradually and connects the beach to the breakwater (Fig. 7a). This results in the formation of a tombolo, which is a spit of sand linking an offshore island to the adjacent coast. The incoming waves or longshore drift transport sediment to the back of the island due to wave refraction. The sediments begin to build up between the beach and the breakwater, creating the bar and effectively tying the breakwater to the mainland. When the ratio is greater than 1.5 , the tombolo does not form. The sediment accumulates in the leeward of the breakwater, forming a tongue-shaped salient. The actual ratio measured from georeferencing-scaled satellite images was 0.571 , indicating conditions for the formation of a tombolo (Fig. 7b). We also checked previous satellite imagery during different periods, which showed that the beach had clearly accumulated outward after the construction of the breakwater. The western sector of the beach is being eroded and is retreating. Despite the eastern sector of the beach increasing, the western sector has been eroding and retreating, and the width of the beach has experienced regression. Intense climate events destroy and damage the communities and infrastructure on the northern sector of the beach.

\section{CONCLUSIONS}

This study demonstrated that UAV-SfM photogrammetry is suitable for the rapid and frequent acquisition of

(a)

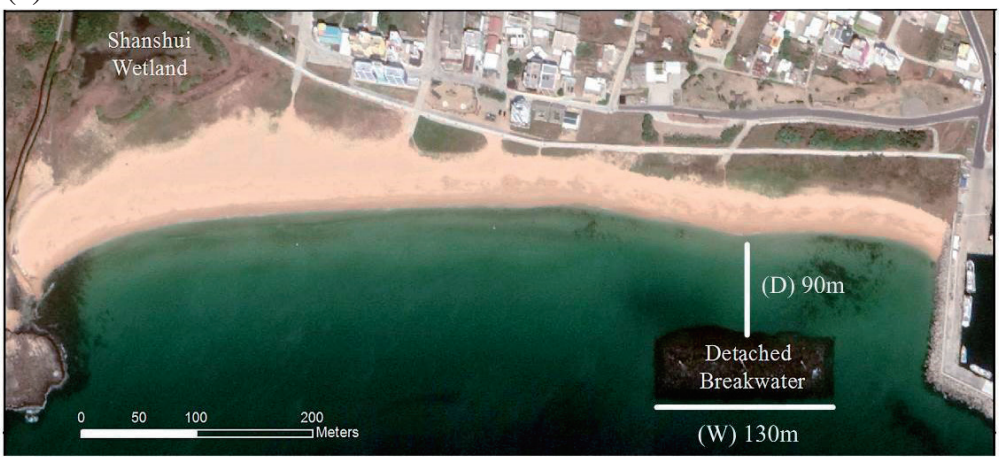

(b)

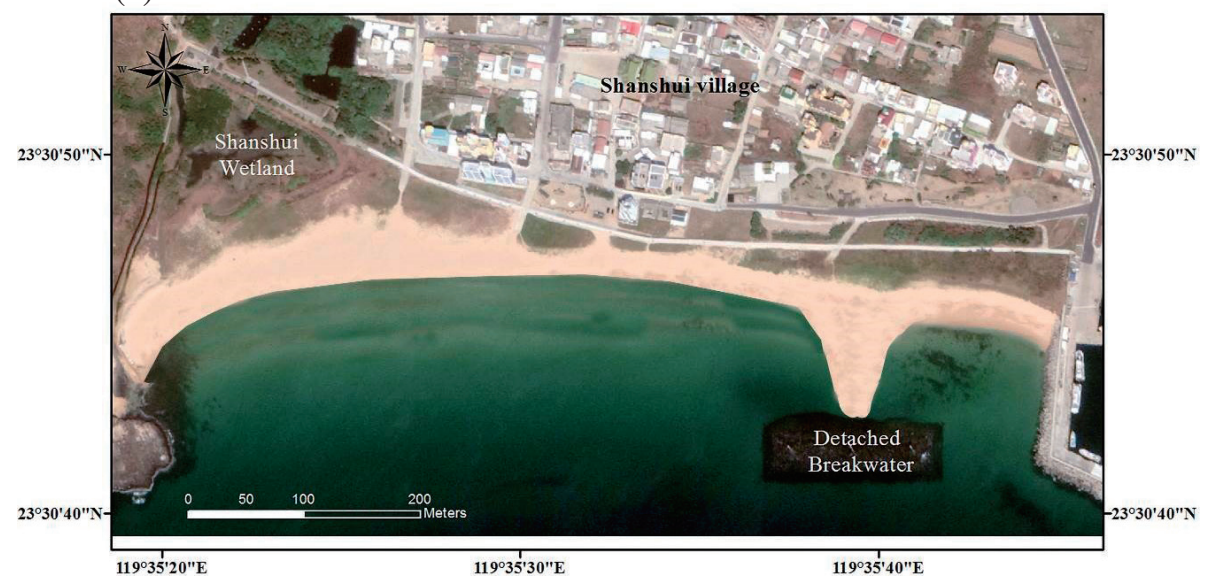

Fig. 7. (a) The distance from the breakwater to the mainland shoreline (D) and the width of the breakwater (W), and the values are 130 and $90 \mathrm{~m}$, respectively. Because the ratio of $(\mathrm{D})$ and $(\mathrm{W})$ is less than 1.5 , a tombolo may form (b). Such dynamic evolution of the beach may cause the retreat of the western shoreline and the erosion of overall beach sand volume. 
3D survey data in the beach environment. We first evaluated the accuracy of UAV-SfM by calculating the horizontal and vertical RMS error of 14 ground control points and 10 checkpoints. The whole RMS error of the checkpoints was $0.081 \mathrm{~m}$ within the $3 \mathrm{D}$ component.

According to the multitemporal DSM dataset obtained from UAV-SfM and the e-GNSS survey, an intense typhoon contributed to clear erosion and retreat of a beach system; however, the system generally recovered through sediment transport processes in winter. The interesting founding is the simultaneous erosion/deposition occurring on the Shanshui beach. The western part of the beach was serious eroded with up to $1.5 \mathrm{~m}$ in height and a large loss of $23254 \mathrm{~m}^{3}$, while the eastern part was in a situation of deposition after the violent typhoon. However, in winter only the western part of the beach was recovered and the eastern part was eroded despite this part is protected by the detached breakwater. Based on the local observation statistics of wave and wind, this may result from the different direction of longshore drift between typhoon and NE monsoon, which may induce the change of the direction of sediment transportation.

Furthermore, beach monitoring reveals that the deformation and changes to Shanshui beach may be associated with the placement of an artificial offshore breakwater. The ratio of the breakwater distance to the mainland shoreline to the width of the breakwater was 0.57 . Therefore, sand will accumulate gradually and the tombolo will likely form. Finally, this study finds that the overall sand volume of this beach was reducing in short-term period. Given that the sand budget of Shanshui beach would have been continuing to reduce, this may be a negative warning to this precious tourism resource. Therefore, we suggest that the management authority should conduct routine beach monitoring and collect the long-term topographical and environmental data to understand the long-term evolution of the beach.

Acknowledgements The authors thank D.-Y. Lin of the National Kaohsiung University of Science and Technology and C.-H. Chen of the National Kaohsiung Normal University for their helpful field experience and valuable advice. This work was financially supported by Ministry of Science and Technology, Taiwan, R.O.C., under grant numbers: 104-2119-M-346-001 (C.-H. Lu).

\section{REFERENCES}

Agisoft, 2018: Agisoft PhotoScan user manual: Professional Edition, Version 1.4, Agisoft LLC, $121 \mathrm{pp}$.

Bird, E. C. F., 1996: Beach Management, John Wiley \& Sons Ltd., 281 pp.

Brunier, G., J. Fleury, E. J. Anthony, A. Gardel, and P. Dussouillez, 2016: Close-range airborne Structurefrom-Motion Photogrammetry for high-resolution beach morphometric surveys: Examples from an em- bayed rotating beach. Geomorphology, 261, 76-88, doi: 10.1016/j.geomorph.2016.02.025. [Link]

Casella, E., A. Rovere, A. Pedroncini, C. P. Stark, M. Casella, M. Ferrari, and M. Firpo, 2016: Drones as tools for monitoring beach topography changes in the Ligurian Sea (NW Mediterranean). Geo-Mar. Lett., 36, 151-163, doi: 10.1007/s00367-016-0435-9. [Link]

Central Weather Bureau, 2016: Statistics of Meteorological Parameter Variations of Taiwan over the Past 50 100 Years, Central Weather Bureau, Taipei City, Taiwan.

Central Weather Bureau, 2017: Tidal Level Statistics, Central Weather Bureau, Taipei City, Taiwan, 637 pp.

Chen, B., Y. Yang, H. Wen, H. Ruan, Z. Zhou, K. Luo, and F. Zhong, 2018: High-resolution monitoring of beach topography and its change using unmanned aerial vehicle imagery. Ocean Coast. Manag., 160, 103-116, doi: 10.1016/j.ocecoaman.2018.04.007. [Link]

Davidson-Arnott, R., 2010: Introduction to Coastal Processes and Geomorphology, Cambridge University Press, $442 \mathrm{pp}$.

Dissanayake, P., J. Brown, P. Wisse, and H. Karunarathna, 2015: Effects of storm clustering on beach/dune evolution. Mar. Geol., 370, 63-75, doi: 10.1016/j.margeo.2015.10.010. [Link]

Gonçalves, J. A. and R. Henriques, 2015: UAV photogrammetry for topographic monitoring of coastal areas. ISPRS J. Photogram. Rem. Sens., 104, 101-111, doi: 10.1016/j.isprsjprs.2015.02.009. [Link]

Gruszczyński, W., W. Matwij, and P. Ćwiąkała, 2017: Comparison of low-altitude UAV photogrammetry with terrestrial laser scanning as data-source methods for terrain covered in low vegetation. ISPRS J. Photogram. Rem. Sens., 126, 168-179, doi: 10.1016/j.isprsjprs.2017.02.015. [Link]

Hanley, M. E., S. P. G. Hoggart, D. J. Simmonds, A. Bichot, M. A. Colangelo, F. Bozzeda, H. Heurtefeux, B. Ondiviela, R. Ostrowski, M. Recio, R. Trude, E. Zawadzka-Kahlau, and R. C. Thompson, 2014: Shifting sands? Coastal protection by sand banks, beaches and dunes. Coast. Eng., 87, 136-146, doi: 10.1016/j.coastaleng.2013.10.020. [Link]

Hanson, H., A. Brampton, M. Capobianco, H. H. Dette, L. Hamm, C. Laustrup, A. Lechuga, and R. Spanhoff, 2002: Beach nourishment projects, practices, and objectives-A European overview. Coast. Eng., 47, 81111, doi: 10.1016/S0378-3839(02)00122-9. [Link]

Hapke, C. J., M. G. Kratzmann, and E. A. Himmelstoss, 2013: Geomorphic and human influence on large-scale coastal change. Geomorphology, 199, 160-170, doi: 10.1016/j.geomorph.2012.11.025. [Link]

Harley, M. D. and P. Ciavola, 2013: Managing local coastal inundation risk using real-time forecasts and artificial dune placements. Coast. Eng., 77, 77-90, doi: 10.1016/j.coastaleng.2013.02.006. [Link] 
Harley, M. D., I. L. Turner, A. D. Short, and R. Ranasinghe, 2011: Assessment and integration of conventional, RTK-GPS and image-derived beach survey methods for daily to decadal coastal monitoring. Coast. Eng., 58, 194-205, doi: 10.1016/j.coastaleng.2010.09.006. [Link]

Javernick, L., J. Brasington, and B. Caruso, 2014: Modeling the topography of shallow braided rivers using Structure-from-Motion photogrammetry. Geomorphology, 213, 166-182, doi: 10.1016/j.geomorph.2014.01.006. [Link]

Lowe, D. G., 2004: Distinctive Image Features from ScaleInvariant Keypoints. Int. J. Comput. Vis., 60, 91-110, doi: 10.1023/B:VISI.0000029664.99615.94. [Link]

Lucieer, A., S. M. de Jong, and D. Turner, 2014: Mapping landslide displacements using Structure from Motion (SfM) and image correlation of multi-temporal UAV photography. Progress in Physical Geography: Earth and Environment, 38, 97-116, doi: 10.1177/0309133313515293. [Link]

Mancini, F., M. Dubbini, M. Gattelli, F. Stecchi, S. Fabbri, and G. Gabbianelli, 2013: Using Unmanned Aerial Vehicles (UAV) for High-Resolution Reconstruction of Topography: The Structure from Motion Approach on Coastal Environments. Remote Sens., 5, 6880-6898, doi: 10.3390/rs5126880. [Link]

Mangor, K., N. K. Drønen, K. H. Kærgaard, and S. E. Kristensen, 2017: Shoreline Management Guidelines, DHI Water \& Environment, 462 pp. Available at https:// www .dhigroup.com/marine-water/ebook-shorelinemanagement-guidelines.

Marriner, N., J. P. Goiran, and C. Morhange, 2008: Alexander the Great's tombolos at Tyre and Alexandria, eastern Mediterranean. Geomorphology, 100, 377-400, doi: 10.1016/j.geomorph.2008.01.013. [Link]

Mason, D. C., C. Gurney, and M. Kennett, 2000: Beach topography mapping-A comparsion of techniques. J. Coast. Conservat., 6, 113-124, doi: 10.1007/ BF02730475. [Link]

Pikelj, K., I. Ružić, S. Ilić, M. R. James, and B. Kordić, 2018: Implementing an efficient beach erosion moni- toring system for coastal management in Croatia. Ocean Coast. Manag., 156, 223-238, doi: 10.1016/j. ocecoaman.2017.11.019. [Link]

Shieh, S.-L., S.-T. Wang, M.-D. Cheng, and T.-C. Yeh, 1998: Tropical Cyclone Tracks over Taiwan from 1897 to 1996 and Their Applications, Central Weather Bureau, Taipei, Taiwan, 467 pp.

Sturdivant, E. J., E. E. Lentz, E. R. Thieler, A. S. Farris, K. M. Weber, D. P. Remsen, S. Miner, and R. E. Henderson, 2017: UAS-SfM for Coastal Research: Geomorphic Feature Extraction and Land Cover Classification from High-Resolution Elevation and Optical Imagery. Remote Sens., 9, doi: 10.3390/rs9101020. [Link]

Sunamura, T. and O. Mizuno, 1987: A study on depositional shoreline forms behind an island. Annual Report of the Institute of Geoscience, the University of Tsukuba, 71-73.

Taveira-Pinto, F., R. Silva, and J. Pais-Barbosa, 2011: Coastal Erosion Along the Portuguese Northwest Coast Due to Changing Sediment Discharges from Rivers and Climate Change. In: Schernewski, G., J. Hofstede, and T. Neumann (Eds.), Global Change and Baltic Coastal Zones, Coastal Research Library, Vol. 1, Springer, Dordrecht, 135-151, doi: 10.1007/978-94007-0400-8_9. [Link]

Vousdoukas, M. I., L. P. M. Almeida, and Ó. Ferreira, 2012: Beach erosion and recovery during consecutive storms at a steep-sloping, meso-tidal beach. Earth Surf. Process. Landf., 37, 583-593, doi: 10.1002/esp.2264. [Link]

Warrick, J. A., A. C. Ritchie, G. Adelman, K. Adelman, and P. W. Limber, 2017: New techniques to measure cliff change from historical oblique aerial photographs and structure-from-motion photogrammetry. J. Coast. Res., 33, 39-55, doi: 10.2112/JCOASTRES-D-16-00095.1. [Link]

Westoby, M. J., M. Lim, M. Hogg, M. J. Pound, L. Dunlop, and J. Woodward, 2018: Cost-effective erosion monitoring of coastal cliffs. Coast. Eng., 138, 152-164, doi: 10.1016/j.coastaleng.2018.04.008. [Link] 